\title{
Workers Compensation Plan
}

National Cancer Institute

\section{Source}

National Cancer Institute. Workers Compensation Plan. NCI Thesaurus. Code C70692.

An insurance program designed to financially compensate an employee in the event of an injury sustained while working. 